\title{
Inflation targeting and term premia estimates for Latin America
}

\author{
Andrew P. Blake ${ }^{1}$ Garreth R. Rule ${ }^{1}$. \\ Ole J. Rummel ${ }^{1}$
}

Received: 2 June 2014/Revised: 4 February 2015/ Accepted: 11 February 2015/

Published online: 11 April 2015

(C) Bank of England 2015. This article is published with open access at Springerlink.com

\begin{abstract}
Inflation targeting has been widely adopted in Latin America. In this paper, we show evidence consistent with major beneficial effects from so doing, with falling term premia and anchored policy rate expectations. To do this we construct term premia estimates using the method suggested by Adrian et al. (2013) for selected inflation targeting Latin American economies. They use synthetic prices constructed from estimated yield curves to derive holding-period excess returns and condition on the principal components of the yields. This approach is extremely easy to implement and fast to calculate. We detect a small drop in interest rate expectations since the global financial crisis but longer term rates seem remarkably well anchored. There is also relatively low correlation between our estimated Latin American and US term premia.
\end{abstract}

Keywords Inflation targeting - Term premia - Affine term structure model

JEL Classification $\quad \mathrm{E} 43 \cdot \mathrm{E} 58 \cdot \mathrm{G} 12 \cdot \mathrm{G} 17$

The views expressed in this paper are those of the authors and should not be taken to be those of the Bank of England or any of its policy committees.

Andrew P. Blake

andrew.blake@bankofengland.co.uk

Garreth R. Rule

garreth.rule@bankofengland.co.uk

Ole J. Rummel

ole.rummel@bankofengland.co.uk

1 Centre for Central Banking Studies, Bank of England, Threadneedle Street,

London EC2R 8AH, UK 


\section{Introduction}

Recently it has become feasible to estimate affine models of the term structure in a routine manner. Such models produce term premia estimates and, therefore, allow us to back out expectations of the future path of short-term interest rates. As such they are extremely useful for the evaluation of the efficacy of monetary policy and the anchoring of interest rate expectations. Several newly available technologies have been proposed to estimate these models, but a particularly attractive one is that of Adrian et al. (2013) (henceforth ACM). Their approach uses OLS to estimate models that previously required maximum likelihood. The 'cost' associated with this is first the necessary use of observable dynamic factors to drive the term structure, and second the use of synthetic bond-price contracts derived from parameterized yield curves. ACM claim extremely good performance compared to more traditional alternatives. It is also computationally very inexpensive. Indeed, the New York Federal Reserve Bank has recently begun publishing daily term premia estimates using this method (see Adrian et al. 2014), complementing the daily publication of the yield curve estimates documented in Gürkaynak et al. (2007).

There is considerable interest in fitting such models. The affine model enables us to calculate implied term premia along the curve and even interest rate expectations, although this requires us to assume that the term premia is the only source of risk compensation. In the last ten years, we have seen considerable turbulence in financial markets and commensurate actions by the US Federal Reserve have necessarily impacted upon Latin America. At the same time the Latin American countries we investigate have been pursuing monetary policy based on inflation targeting, with apparent success. We compare the results across countries where we have used no common information in the estimation. Interestingly, we find that long-run interest rate expectations remain stable in each country while movements in the term premia account for most of the observed variation in yields. The variation in term premia is remarkably similar across countries, indicating that a common factor seems to be at work. In several cases term premia correlates with the US, with comovement at particular events. Regional correlations are strong, and although the US affects Latin American countries in predicable ways the dominant effect seems to be from domestic monetary policy.

Our analysis cannot prove by itself that inflation targeting has been the main driver of improved economic conditions. There have been a number of complementary recent studies analyzing Latin American term structures such as De Pooter et al. (2014), Ceballos et al. (2014), and Guarn et al. (2014) which are consistent with our findings and the hypothesis that improved monetary policy has at least partly been the cause. De Pooter et al. (2014) in particular show that Latin American inflation expectations are strongly anchored. As Ellingsen and Söderström (2001) discuss, long-run nominal rates reflect expected policy rates, term premia and inflation expectations. Decomposing the yield curve into policy rate expectations and term premia allows us to further investigate the evolution of policy credibility in Latin America. But as Gürkaynak (2014) lucidly makes clear, the 
precise cause of the fall in, say, inflation expectations remains unexplained. Our paper is another piece of evidence that inflation targeting has been a significant driver. ${ }^{1}$

In what follows, we apply the ACM method to four inflation targeting Latin American economies, using monthly zero-coupon yield data from Chile, Colombia, Mexico and Peru from 2005 to 2014, encompassing the global financial crisis and aftermath. We also report selected results for the US and Brazil. We obtain observable factors as the principal components of the term structure itself, and estimate Nelson-Siegel yield curves for each to provide the necessary synthetic contracts. The resulting curves allow us to fit affine models in a few seconds and the complete procedure is extremely easy to automate. To further anticipate our results we find that long-term policy rate expectations are solidly anchored for each of the four selected countries. This accords with a story of credible monetary policies linked to well-understood inflation targets. Almost all variations in yields are attributed to variation in term premia.

The present paper is organized as follows. The next section outlines the collection of methods used, both for yield curve estimation and for the ACM estimates. Sections 3 and 4 contain our empirical analysis, using Colombian data as an illustration for the methods before discussing the term premia estimates and their behavior. A final Sect. 5 concludes.

\section{Econometric approach}

The interesting results here are the estimated term premia, but these are obtained using a multi-step process. We first outline the general approach we use, briefly describing the Nelson and Siegel (1987) method and then the less familiar affine model and ACM estimation approach in more detail. Although we need to use a multi-step approach to generate the required data, each step is conceptually simple and provides information that is interesting in its own right.

\subsection{Nelson-Siegel method}

It is often useful to have parsimonious models of yield curves, and there have been a number of suggested methods. In particular, Nelson and Siegel (1987) proposed an extremely simple cross-sectional approach to the estimation of yields curves. They simply fit

$$
y_{\tau}=\theta_{0}+\theta_{1}\left(\frac{1-e^{-v \tau}}{v \tau}\right)+\theta_{2}\left(\frac{1-e^{-v \tau}}{\nu \tau}-e^{-v \tau}\right)
$$

across the available maturity dimension $\tau$, and the three terms have become associated with the level, slope and curvature of the yield curve. The four parameters of

\footnotetext{
${ }^{1}$ In an ideal world (and as suggested by a referee) we would have used selected non-inflation targeting countries as a control group, but data available to us on Bloomberg were of insufficiently good quality to build satisfactory models. Even then, the spillovers from neighbors with 'good' monetary policy could make it difficult to be conclusive. Much further work is clearly required.
} 
the model $\left(\theta_{0}, \theta_{1}, \theta_{2}\right.$ and $\left.v\right)$ are often fit using nonlinear least squares, sometimes weighted by (inverse) duration. A second curvature term was proposed by Svensson (1995) and is often used. Diebold and Rudebusch (2013) give an excellent description of this and related methods.

Although we experimented with the Svensson extension the simplest specification was easily adequate, so we use Nelson-Siegel curves throughout. This is similar to Gürkaynak et al. (2007) who use Nelson-Siegel curves for US Treasuries until the end of 1979 and Svensson curves thereafter. We provide evidence of the fit below. Once constructed we can then generate yields in any period for any value of $\tau$. Thus for any month-end data, say September 2010, we can calculate implied contracts for any $\tau$ and then use the data from end-October for the relevant monthsto-go. Essentially we are able to calculate relative fixed event yields without the actual data. This is a key input into the ACM estimation procedure that enables us to price using linear regressions.

\subsection{Affine models of yields}

Affine models, for example Ang and Piazzesi (2003), make the following assumptions about what drives the term structure. Each yield curve depends on a set of factors, $Z_{t}$, which can be either macro-factors or some implied state variables. We will assume that these factors can be adequately modeled using a simple firstorder VAR such as

$$
Z_{t+1}=\mu+\Phi Z_{t}+v_{t+1}, v_{t+1} \sim N(0, \Sigma) .
$$

In what follows, the factors are obtained as the principal components of the implied term structure.

Now we make the important modeling assumptions about how the prices of bonds are determined. The pricing equations are constructed using the recursive structure implied by the yield curve itself under the assumption of no-arbitrage, and are given by

$$
P_{t}^{n}=E_{t}\left[M_{t+1} P_{t+1}^{n-1}\right]
$$

where $P_{t}^{n}$ is the price of a discount bond in period $t$ with $n$ periods to go and $M_{t}$ is a suitable stochastic discount factor. The values of $n$ in effect discretize the durations above with a unit being the sampling period. In logs, and making the assumption of log-normal shocks, we can write (2) as

$$
p_{t}^{n}=E_{t}\left[m_{t+1}+p_{t+1}^{n-1}\right]+\frac{1}{2} \operatorname{var}_{t}\left[m_{t+1}+p_{t+1}^{n-1}\right]
$$

where lower case denotes the log of the upper case equivalent and we use the fact that if $k=\ln K$, then $\ln E_{t}[K]=E_{t}[k]+\frac{1}{2} \sigma_{k, t}$.

In turn, the stochastic discount factor is defined in logs as

$$
m_{t+1}=-r_{t}-\frac{1}{2} \lambda_{t}^{\prime} \lambda_{t}-\lambda_{t}^{\prime} \Sigma^{-\frac{1}{2}} v_{t+1}
$$


with the risk-pricing terms given by

$$
\lambda_{t}=\Sigma^{-\frac{1}{2}}\left(\lambda_{0}+\lambda_{1} Z_{t}\right) .
$$

As Ang and Piazzesi (2003) and many others discuss, this gives a tractable formulation of the discount factor that has predictable effects, although it is not necessarily consistent with the assumptions we make elsewhere in the model about the implied form of the discount factor. Log prices themselves are assumed affine in the state variables

$$
p_{t}^{n}=-A_{n}-B_{n}^{\prime} Z_{t}
$$

and equivalently $p_{t+1}^{n-1}=-A_{n-1}-B_{n-1}^{\prime} Z_{t+1}$. This powerful setup allows for time varying price of risk terms through the state dependency of $\lambda_{t}$.

We need relatively little more to derive a recursive structure for the parameters of the yield curve. Equating (3) and (5) given (4) yields

$$
\begin{aligned}
A_{n}+B_{n}^{\prime} Z_{t}= & -E_{t}\left[-r_{t}-\frac{1}{2} \lambda_{t}^{\prime} \lambda_{t}-\lambda_{t}^{\prime} \Sigma^{-\frac{1}{2}} v_{t+1}-A_{n-1}-B_{n-1}^{\prime} Z_{t+1}\right] \\
& -\frac{1}{2} \operatorname{var}_{t}\left[-r_{t}-\frac{1}{2} \lambda_{t}^{\prime} \lambda_{t}-\lambda_{t}^{\prime} \Sigma^{-\frac{1}{2}} v_{t+1}-A_{n-1}-B_{n-1}^{\prime} Z_{t+1}\right] \\
& =r_{t}+\frac{1}{2} \lambda_{t}^{\prime} \lambda_{t}+A_{n-1}+B_{n-1}^{\prime} \Phi Z_{t}-\frac{1}{2} \operatorname{var}\left[\left(\lambda_{t}^{\prime}+B_{n-1}^{\prime}\right) \Sigma^{\frac{1}{2}} v_{t+1}\right] \\
& =r_{t}+\frac{1}{2} \lambda_{t}^{\prime} \lambda_{t}+A_{n-1}+B_{n-1}^{\prime} \Phi Z_{t}-\frac{1}{2}\left(\lambda_{t}^{\prime}+B_{n-1}^{\prime}\right) \Sigma^{-1}\left(\lambda_{t}+B_{n-1}\right)
\end{aligned}
$$

Taking expectations appropriately and dropping the conditionality of the variance operator yields the last line straightforwardly.

Finally, the short rate is assumed to be

$$
r_{t}=p_{t}^{1}
$$

and modeled as

$$
r_{t}=\delta_{0}+\delta_{1}^{\prime} Z_{t}
$$

This is again an affine function of the factors. Collecting terms we obtain

$$
\begin{aligned}
A_{n}+B_{n}^{\prime} Z_{t}= & \left(\delta_{0}+A_{n-1}-\frac{1}{2} B_{n-1}^{\prime} \Sigma B_{n-1}\right) \\
& +\left(\delta_{1}^{\prime}+B_{n-1}^{\prime} \Phi\right) Z_{t}-B_{n-1}^{\prime} \Sigma \lambda_{t}
\end{aligned}
$$

The two terms in $\frac{1}{2} \lambda_{t}^{\prime} \lambda_{t}$ cancel, leaving us with a single term in $\lambda_{t}$. Now equate terms and obtain

$$
\begin{gathered}
A_{n}=\delta_{0}+A_{n-1}-B_{n-1}^{\prime} \Sigma \lambda_{0}-\frac{1}{2} B_{n-1}^{\prime} \Sigma B_{n-1} \\
B_{n}^{\prime}=\delta_{1}^{\prime}+B_{n-1}^{\prime}\left(\Phi-\Sigma \lambda_{1}^{\prime}\right) .
\end{gathered}
$$


These coefficients together with the model of the factors generate future bond prices [(see for example Wickens (2008), Chapter 11]. Prices can be converted easily into yields, consistent with the Nelson-Siegel curves.

We can also derive the implied risk neutral curves by setting the price of risk terms $\lambda_{0}$ and $\lambda_{1}$ to zero. Thus an equivalent recursion consisting of

$$
\begin{gathered}
A_{n}=\delta_{0}+A_{n-1}-\frac{1}{2} B_{n-1}^{\prime} \Sigma B_{n-1} \\
B_{n}^{\prime}=\delta_{1}^{\prime}+B_{n-1}^{\prime} \Phi .
\end{gathered}
$$

generates the implied expected prices. Again these can be converted into expected yields and a similar formula gives expected interest rates. These are discussed in detail in, for example, Joyce et al. (2010). Essentially we need to program up additional recursions in the same form as (7) and (8) or (9) and (10). As noted in the introduction the term premium is assumed to be the only source of risk compensation and it is this which allows us to easily back out interest rate expectations.

\subsection{The ACM approach}

The model above has a number of parameters to estimate, and is often fitted using maximum likelihood methods under suitable identifying restrictions. As we noted above, ACM first assume that the factors can be observed and estimate the factor model independently of the other parameters. This will be done by taking principal components of the term structure itself. Second, they define the ex-post holdingperiod excess return as

$$
x_{t+1}^{n-1}=p_{t+1}^{n-1}-p_{t}^{n}-r_{t} .
$$

The major contribution of ACM is to show that

$$
1=E_{t}\left[\exp \left(x_{t+1}^{n-1}-\frac{1}{2} \lambda_{t}^{\prime} \lambda_{t}-\lambda_{t}^{\prime} \Sigma^{-\frac{1}{2}} v_{t+1}\right)\right]
$$

and

$$
E_{t}\left[x_{t+1}^{n-1}\right]=\operatorname{cov}_{t}\left(x_{t+1}^{n-1}, v_{t+1}^{\prime} \Sigma^{-\frac{1}{2}} \lambda_{t}\right)-\frac{1}{2} \operatorname{var}_{t}\left(x_{t+1}^{n-1}\right)
$$

must hold. They then define

$$
\beta_{t}^{n-1}=\Sigma^{-\frac{1}{2}} \operatorname{cov}_{t}\left(v_{t+1}^{\prime},\left(x_{t+1}^{n-1}\right)^{\prime}\right)
$$

so we can re-write (13) as

$$
E_{t}\left[x_{t+1}^{n-1}\right]=\left(\beta_{t}^{n-1}\right)^{\prime}\left(\lambda_{0}+\lambda_{1} Z_{t}\right)-\frac{1}{2} \operatorname{var}_{t}\left(x_{t+1}^{n-1}\right) .
$$

Following on from this ACM obtain 


$$
x_{t+1}^{n-1}-E_{t}\left[x_{t+1}^{n-1}\right]=\left(\gamma_{t}^{n-1}\right)^{\prime} v_{t+1}+e_{t+1}^{n-1}
$$

which after a little manipulation gives

$$
\begin{aligned}
\underbrace{x_{t+1}^{n-1}}_{\text {Excess return }}= & \underbrace{\left(\beta_{t}^{n-1}\right)^{\prime}\left(\lambda_{0}+\lambda_{1} Z_{t}\right)}_{\text {Expected return }}-\underbrace{\frac{1}{2}\left(\beta_{t}^{n-1}\right)^{\prime} \Sigma\left(\beta_{t}^{n-1}\right)}_{\text {Convexity adjustment }} \\
& +\underbrace{\left(\beta_{t}^{n-1}\right)^{\prime} v_{t+1}}_{\text {Priced innovation }}+\underbrace{e_{t+1}^{n-1}}_{\text {Pricing error }} .
\end{aligned}
$$

This expression is the key to the ACM simplification of the estimation procedure. Stack it to give

$$
x=\beta^{\prime}\left(\lambda_{0}+\lambda_{1} Z_{-}\right)-\frac{1}{2}\left(B^{*} \operatorname{vec}(\Sigma)+\sigma^{2}\right)+\beta^{\prime} V+e
$$

where

$$
Z_{-}=\left[\begin{array}{llll}
Z_{0} & Z_{1} & \ldots & Z_{T-1}
\end{array}\right], V=\left[\begin{array}{llll}
v_{1} & v_{2} & \ldots & v_{T}
\end{array}\right]
$$

and

$$
\beta=\left[\begin{array}{llll}
\beta^{1} & \beta^{2} & \ldots & \beta^{N}
\end{array}\right]
$$

and we define

$$
B^{*}=\left[\operatorname{vec}\left(\beta^{1}\left(\beta^{1}\right)^{\prime}\right) \operatorname{vec}\left(\beta^{2}\left(\beta^{2}\right)^{\prime}\right) \ldots \operatorname{vec}\left(\beta^{N}\left(\beta^{N}\right)^{\prime}\right)\right]
$$

which follows the notation adopted by ACM.

If we can condition on known $Z$ and $x$ then only $\lambda$ and $\beta$ in (18) need estimating. ACM suggest taking $n$ principal components of the term structure data and using these as the $Z$ variables. Additionally we can calculate $x$ from some appropriately parameterized pricing curves, and, of course, Nelson-Siegel curves are suitable.

ACM suggest a three-step estimation procedure:

1. Estimate the factor model (1) from the principal components of the (observed) yields. Retrieve the estimated residuals, $\widehat{V}$, and residual covariance, $\widehat{\Sigma}$.

2. Estimate the equation

$$
x=a+c Z_{-}+\beta^{\prime} \widehat{V}+e
$$

by least squares where $e$ is the matrix of residuals. This gives estimates for $\widehat{a}, \widehat{c}$ and $\widehat{\beta}$ as well as $\widehat{\sigma}$ from $\operatorname{tr}\left(\widehat{e} \widehat{e}^{\prime}\right) / T$.

3. From (18) we know that $\beta^{\prime} \lambda_{1}=c$ and $\beta^{\prime} \lambda_{0}=a+\frac{1}{2}\left(B^{*} \operatorname{vec}(\Sigma)+\sigma^{2}\right)$ in expectation. Given that, we can estimate the price of risk terms using

$$
\widehat{\lambda}_{1}=\left(\widehat{\beta} \widehat{\beta}^{\prime}\right)^{-1} \widehat{\beta}^{\prime} \widehat{c}
$$


and

$$
\widehat{\lambda}_{0}=\left(\widehat{\beta} \widehat{\beta}^{\prime}\right)^{-1} \widehat{\beta}^{\prime}\left(\widehat{a}+\frac{1}{2}\left(\widehat{B}^{*} \operatorname{vec}(\widehat{\Sigma})+\widehat{\sigma}^{2}\right)\right) .
$$

This approach is incredibly simple, and can be coded in comparatively few lines. ${ }^{2}$ More than this, it is many orders of magnitude less expensive to calculate relative to the maximum likelihood approach, and makes cross-country analysis very straightforward. In the next section, as way of illustration we apply the methods step-by-step to Colombian data before comparing the results across countries.

\section{Data and yield curve estimation}

We use a single country, Colombia, just to illustrate the methods. The results for each country were very similar. Daily zero coupon benchmark yields were obtained from Bloomberg for the four countries. We converted these to end-month values and fitted separate Nelson-Siegel curves to each time period and country. For example, the data for Colombia for the 3-, 6-, 12-, 24-, 36-, 48-, 60-, 96- and 120-month yields from May 2006 through May 2014 are shown in Fig. 1.

We fit $^{3}$ Nelson-Siegel curves to the cross sections, and the resulting implied yields are as shown in Figure 2. These are a remarkably close fit, which justifies the choice of the simplest Nelson-Siegel specification. This gives us all of the implied contracts for the intermediate periods which can be obtained by appropriate choice of $\tau$. Similar fits are obtained for all four countries.

\section{ACM results}

We follow the exact three-step procedure adopted by ACM. This requires us to obtain the principal components, determine an appropriate number to use, calculate the holding-period excess returns and then fit the $\lambda$ values. From these we can calculate the implied affine yield curves, term premia, the implied risk neutral curves and hence interest rate expectations.

\subsection{Principal components}

For each country we first calculate the implied yield curve from three months to ten years at three-month intervals. We then take the principal components of these to use as the factors. In general we find that we need four factors to fit a near-perfect affine model in each case. For Colombia these are shown in Fig. 3 and labeled Component 1-4 for the first to fourth component. The components themselves have

\footnotetext{
${ }^{2}$ We coded the procedure in EViews 7.2. This has the advantage of handling the data very well, so that we can, for example, vary the periodicity of the estimates easily.

${ }^{3}$ The model is very easy to fit, and we did so in Excel.
} 


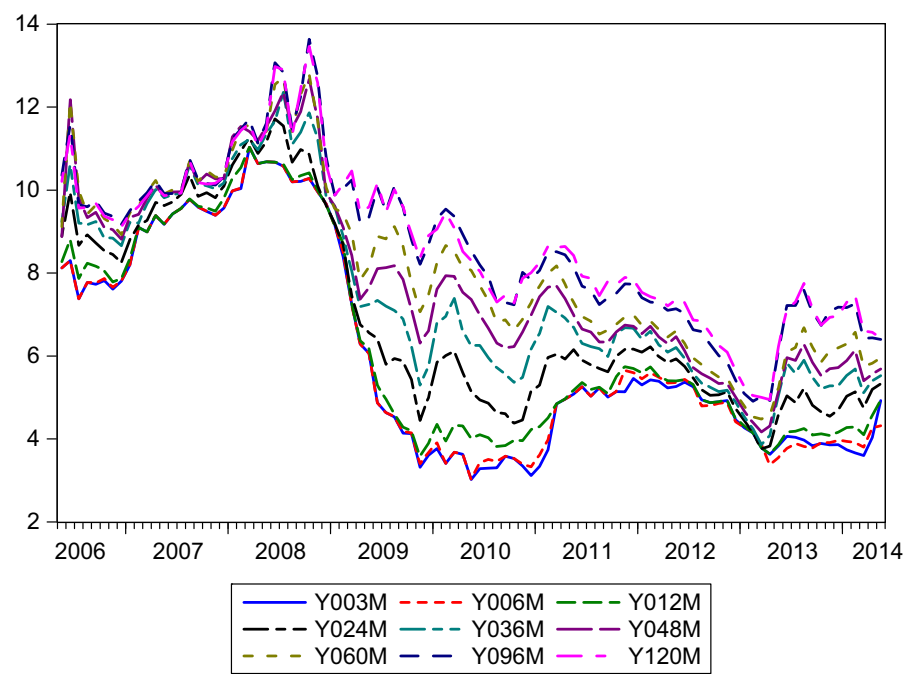

Fig. 1 Colombian yield curve data. Source Bloomberg

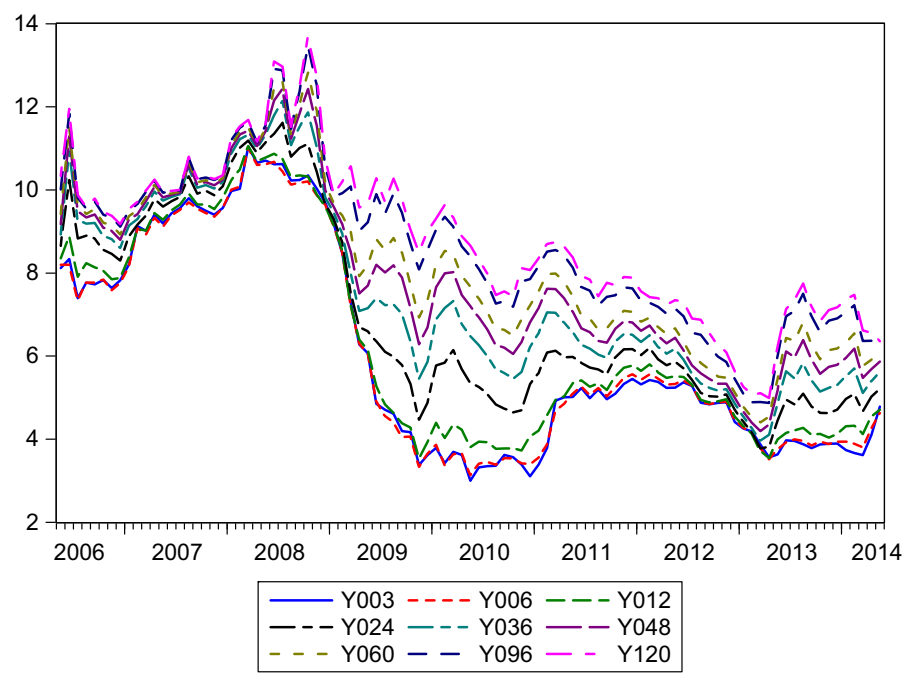

Fig. 2 Colombian yields implied by the Nelson-Siegel model. Source Authors' calculations from Bloomberg data

no direct interpretation, but the first factor clearly contains information for the implied levels. It is not generally possible to associate the factors with the NelsonSiegel factors for example. Using the fourth factor typically allows us to improve the fit of the short end of the yield curve. ${ }^{4}$

\footnotetext{
4 ACM use a five-factor model, but they use Nelson-Siegel-Svensson curves which have an additional term. A fifth factor makes almost no difference to our estimates.
} 


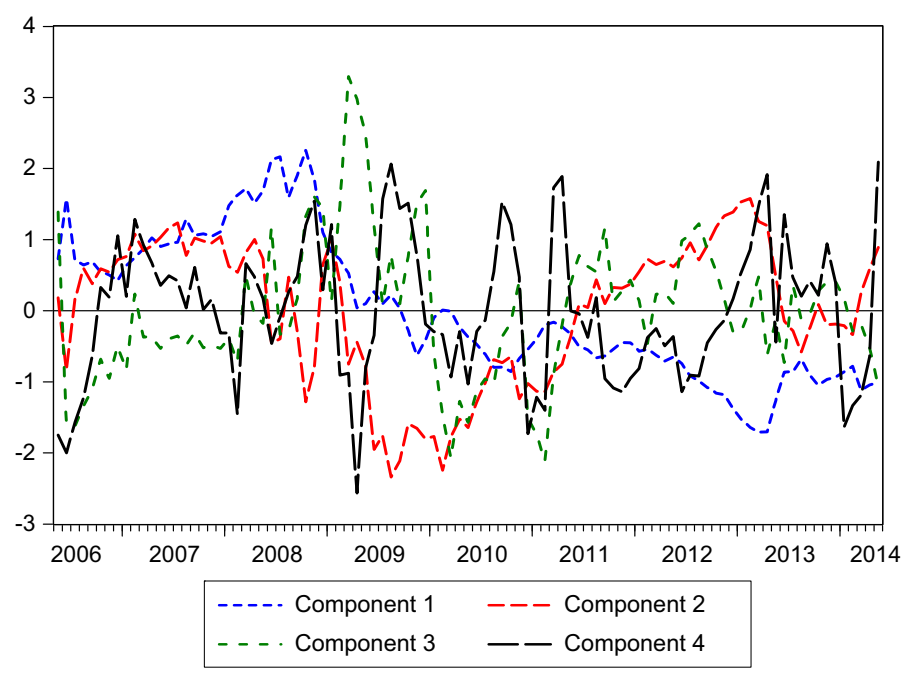

Fig. 3 Colombian principal components. Source Authors' calculations

\subsection{Affine yield curves}

Four principal components were used as observed factors for each country, and the ACM three-step procedure followed. ${ }^{5}$ The resulting affine models fit the yields quite satisfactorily. Here we plot three representative cross sections in Fig. 4 for the Colombian data above in March 2008, December 2010 and December 2012. These correspond to periods before, during and since the financial crisis. The lowest line in each graph is the implied risk neutral curve where the values of $\lambda$ have been set to zero and agents are, therefore, not seeking compensation for risk. This can be seen to deviate in all cases quite sharply from the empirical curves. As should be evident from these examples this is a very satisfactory fit for an affine model, with the Colombian model often the worst in terms of pricing errors, and we can replicate a sequence of individually estimated Nelson-Siegel curves with relatively few parameters and the principal components.

\subsection{Term premia and expected interest rates}

It is central to our analysis that the four countries that we study are all inflation targeters, see Hammond (2012). Currently Chile, Colombia and Mexico all have inflation targets of $3 \%$ (within a target band) and Peru has a central target of $2 \%$. This generates steady-state predictions for policy rates, as credible inflation targets should be associated with an appropriate long-run nominal interest rate. In particular we expect longer dated expected nominal interest rate in Peru to be lower than the

\footnotetext{
5 As suggested by ACM we set the constant $(\mu)$ in the VAR to zero, which is appropriate for stationary data. This has a small effect on, for example, the estimated long-run interest rate, but has no effect on the correlation results.
} 

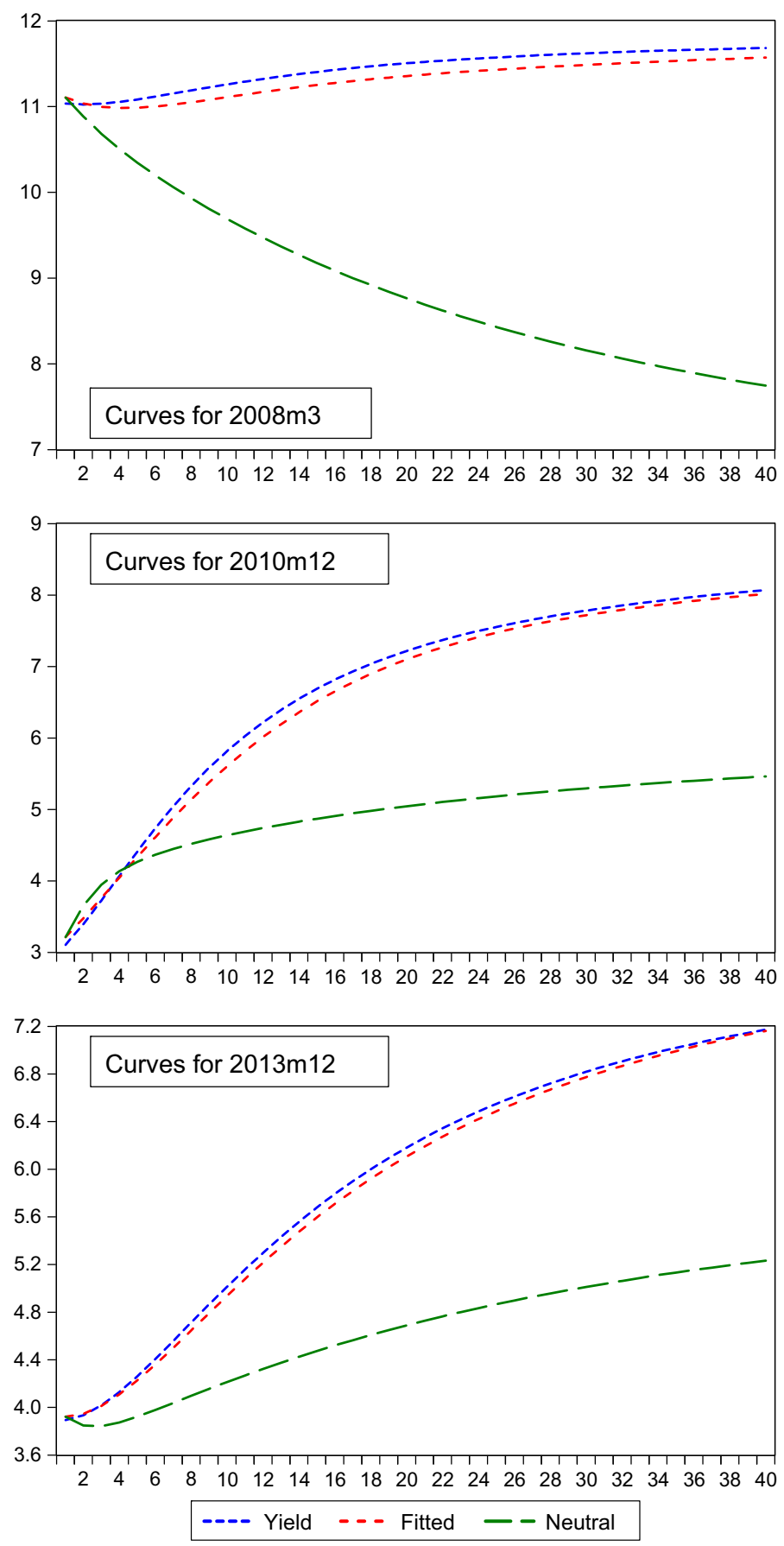

Fig. 4 Yield curves: Nelson-Siegel, affine and risk neutral. Source Authors' calculations 
other three to give a similar equilibrium real interest rate. We should also note that in the mid-2000 s Mexican and Colombian policy rates were markedly higher than the other two.

Our sample periods are slightly different for each country which reflects data availability, all ending in May 2014. Chile runs from October 2006, Colombia (as noted above) from May 2006, Mexico from January 2006 and Peru from May 2006. This gives around 95 observations per country. ${ }^{6}$ We now discuss the country results in turn, where we plot the yield, the term premium and the expected interest rate at 2-, 5- and 10-year horizons for each.

Chile (Fig. 5) has perhaps the least interesting graphs but the most interesting results; the expected rate asymptotes very quickly to approximately $5 \%$ on an annual basis. Term premia have markedly declined over the last decade, with some variation around the financial crisis and some evidence that they went negative at the shortest horizon. The dynamics of the term structure seem to imply unusually rapid convergence to the long run. However, they are extremely good news for Chilean monetary policy makers, where long-run interest rate expectations are strongly anchored in the very near future. Notice that estimated term premia have recently remained low.

The story is similar in Colombia (Fig. 6), and here it is perhaps more surprising as interest rates started higher. However, long-term expectations of the policy rate are solidly anchored, perhaps slightly higher than for Chile, but nonetheless with little sign of any change throughout the estimation period as can be seen in the 10 -year (green) line. The higher yields in the long run for the early years of the sample are attributed by the model entirely to term premia. We return to the dynamics of this when we consider correlations with US premia below.

Mexico (Fig. 7) mirrors Colombia; term premia are slightly higher, expected interest rates slightly lower. There is some evidence of a more elevated term premium in the recent past, but otherwise the graphs are remarkably similar. Peru (Fig. 8), with a lower inflation target delivers the lowest anticipated future interest rate as expected, around $4 \%$ rather than the $5 \%$ or more in the other three countries. Term premia are more volatile, but as with Chile, all movements in the yields further out are attributable to term premia effects and not interest rate expectations.

As an additional exercise we controlled for the effects of turbulence in financial markets over the crisis period by shortening the sample period by three years, so that the samples all begin in 2009. At our monthly frequency this gives around 60 observations on stationary data, enough for reasonable inference. To illustrate the results, we give the average of the ten-year expected rates in Table 1. Not only are these the averages, they are also the expected values in every period as ten-year expectations are extremely flat across the estimation sample. For the three inflation targeters that target inflation at $3 \%$ the long-run expected interest rate is

\footnotetext{
${ }^{6}$ In the majority of cases the yield data used in the estimation is from the last working day of the month. The exception is a small number of cases for Chile; here the month-end data was either unavailable or appeared to be entered into Bloomberg incorrectly (i.e., there were random spikes in the three- and sixmonth data which were not present in longer maturity yields). In these cases a day earlier in the month has been used. For all four countries we used the sample of yields described for the Colombian case.
} 

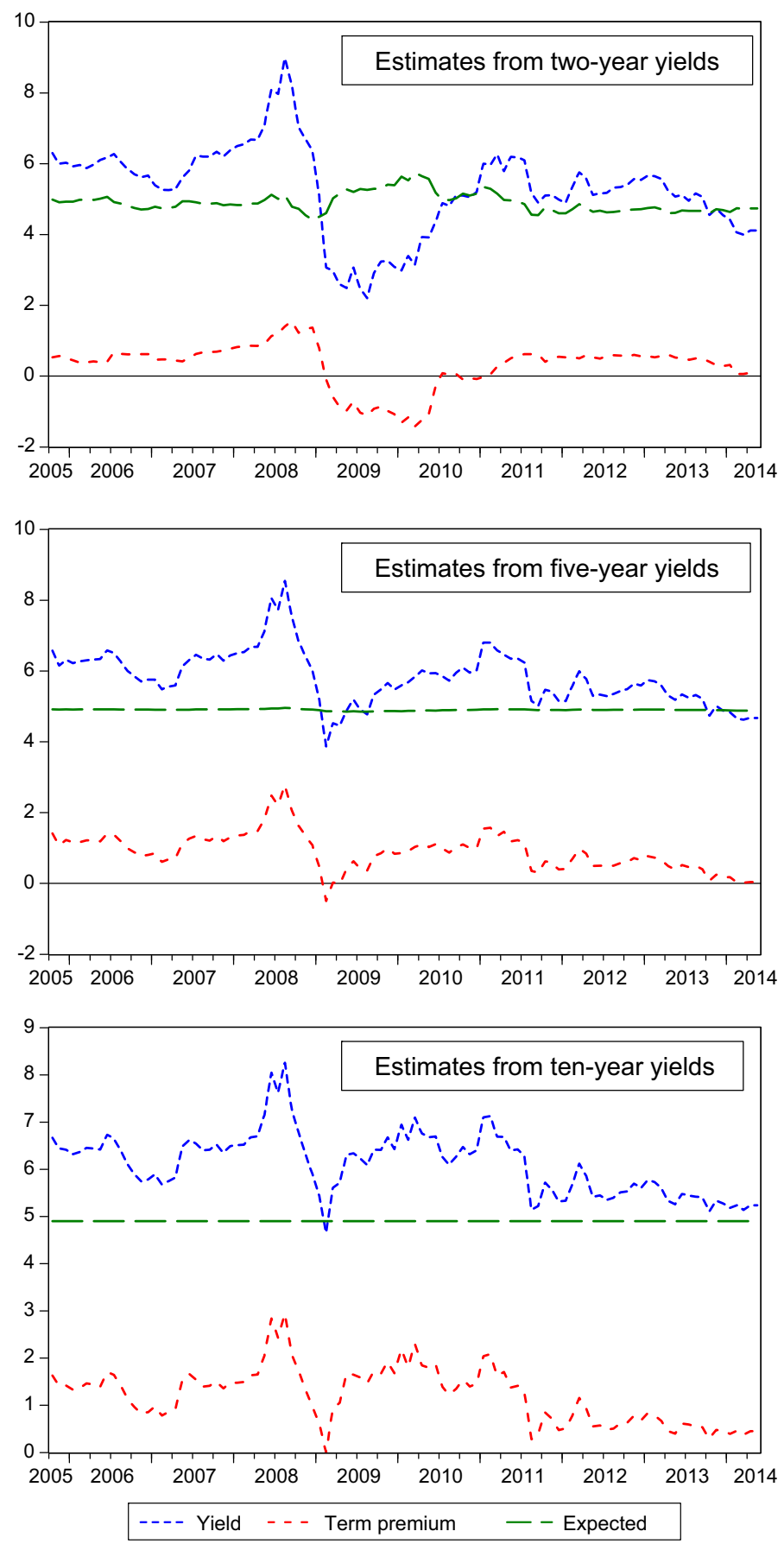

Fig. 5 Chile. Source Authors' calculations from Bloomberg data 

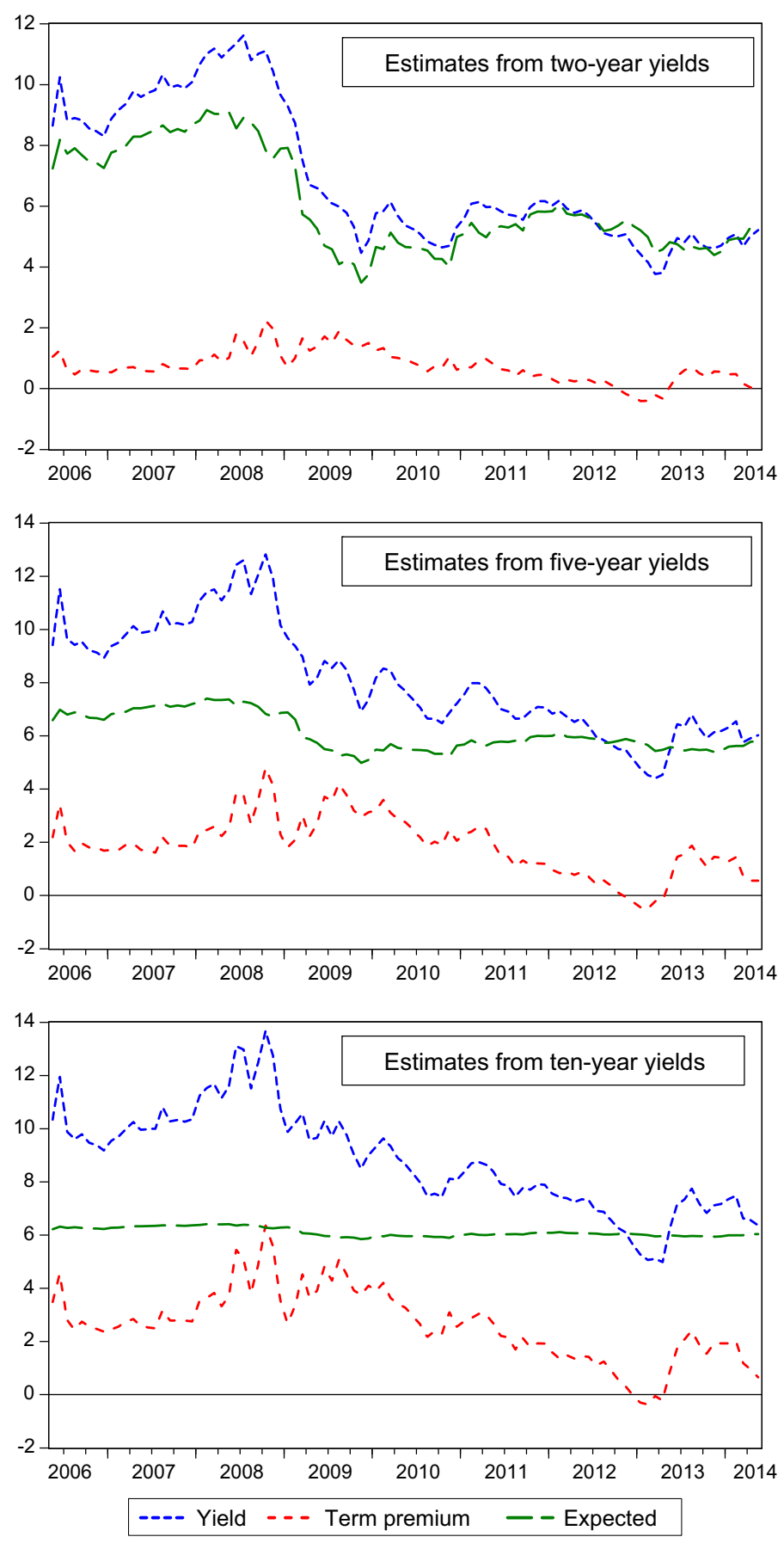

Fig. 6 Colombia. Source Authors' calculations from Bloomberg data 

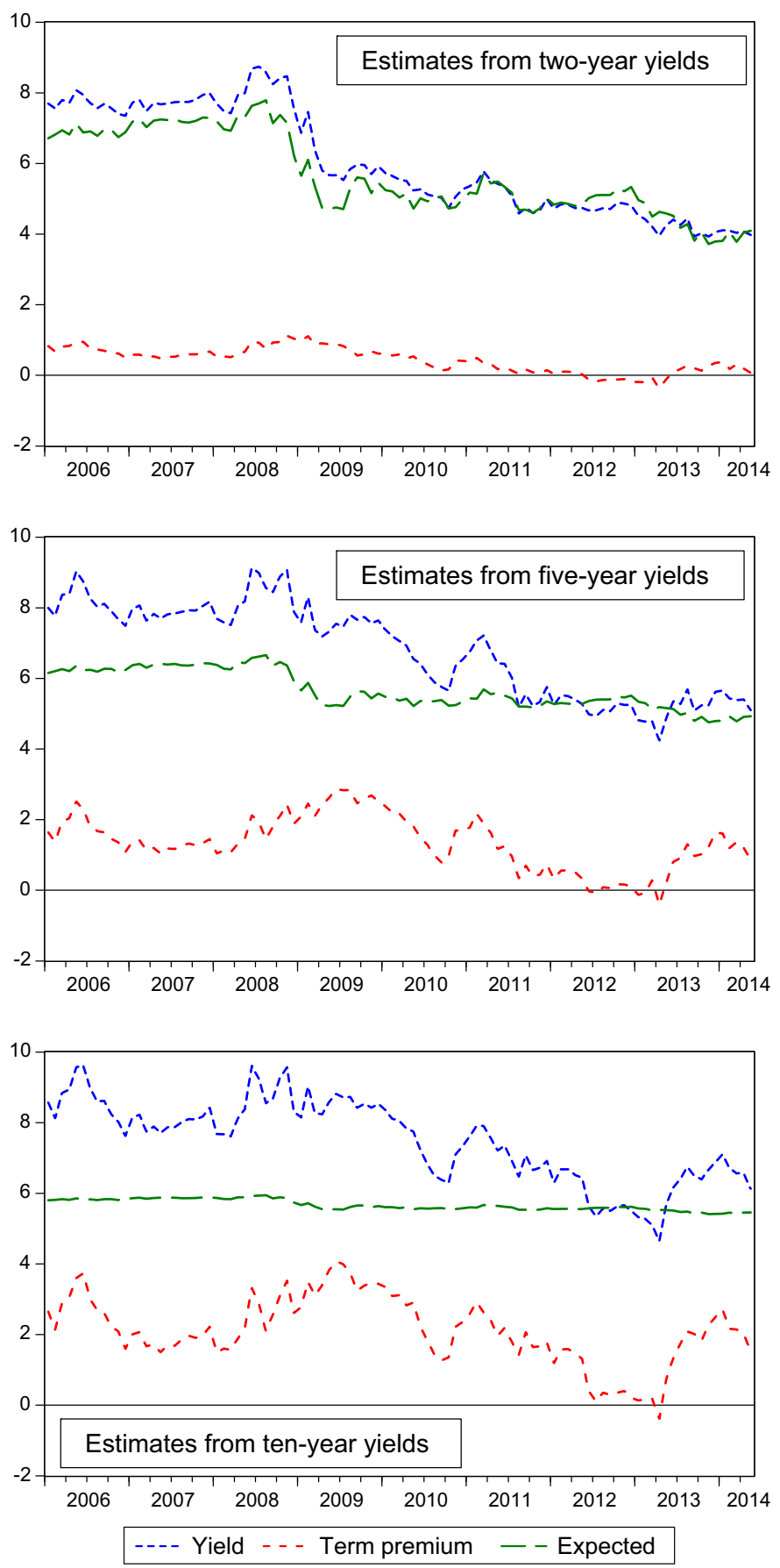

Fig. 7 Mexico. Source Authors' calculations from Bloomberg data 

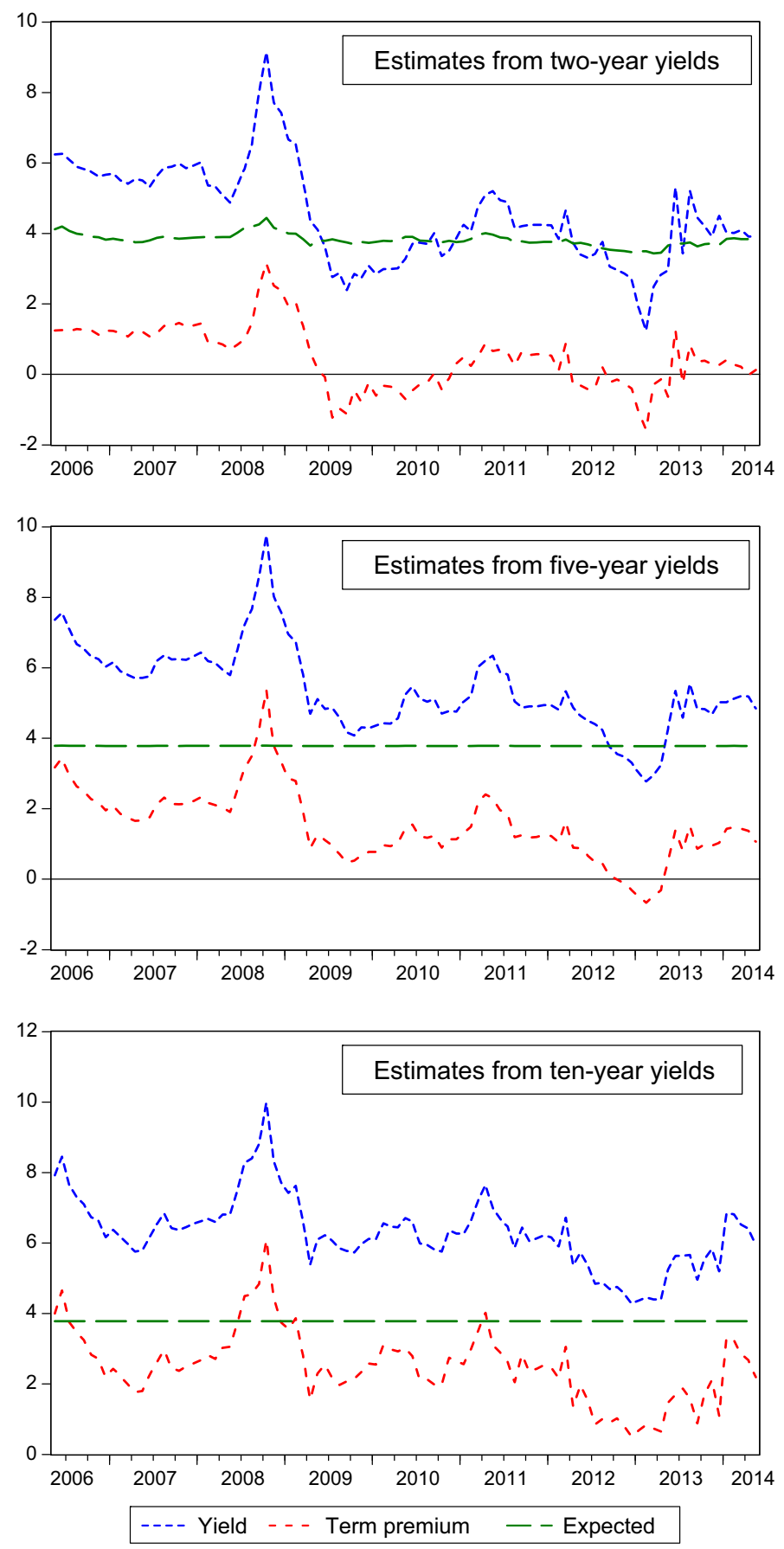

Fig. 8 Peru. Source Authors' calculations from Bloomberg data 
Table 1 Short sample expected rates 10 years out, annualized. Source Authors' calculations
Average 10 year expected rates

\begin{tabular}{ll}
\hline Chile & $4.3 \%$ \\
Colombia & $4.3 \%$ \\
Mexico & $4.5 \%$ \\
Peru & $3.3 \%$ \\
\hline
\end{tabular}

Table 2 Two-year term premia cross correlations. Source Authors' calculations
Absolute $t$ statistics in parenthesis

\begin{tabular}{lllllll}
\hline & US & Brazil & Chile & Colombia & Mexico & Peru \\
\hline US & 1 & & & & & \\
& - & & & & & \\
Brazil & 0.41 & 1 & & & & \\
& $(4.34)$ & - & & & & \\
Chile & -0.49 & 0.20 & 1 & & & \\
& $(5.62)$ & $(1.99)$ & - & & & \\
Colombia & 0.70 & 0.48 & -0.30 & 1 & & \\
& $(9.57)$ & $(5.28)$ & $(3.01)$ & - & & \\
Mexico & 0.40 & 0.39 & -0.17 & 0.83 & 1 & \\
& $(4.38)$ & $(4.12)$ & $(1.68)$ & $(14.70)$ & - & \\
Peru & -0.09 & 0.37 & 0.29 & 0.29 & 0.49 & 1 \\
& $(0.88)$ & $(3.89)$ & $(2.96)$ & $(3.00)$ & $(5.46)$ & - \\
\hline
\end{tabular}

approximately $4.4 \%$. For Peru, targeting inflation a percentage point lower, the expected interest rate is $3.3 \% 10$ years out. These numbers are lower than for the full sample by around a percentage point, but are extraordinarily consistent with each other, suggesting long-run real rates of about $1.5 \%$ in every case. This seems a little low, and we prefer the full sample estimates, but the message is the same. Policy rate expectations are extremely well anchored in each case. To sum up; inflation targeting appears to be working very well in these countries.

\subsection{Correlations}

If interest rate expectations are so well anchored by four entirely independent monetary policies, it is interesting to ask how the term premia are correlated, both between themselves and with the US on the assumption that the US is the dominant financial center. Note that the US Federal Reserve reacted strongly to a domestic and then global financial crisis with a variety of conventional and unconventional means. For convenience we plot all four of our estimated ten-year term premia together with the equivalent US term premia obtained from Adrian et al. (2014) in Fig. 9.

Inspecting the levels of the term premia gives us an interesting insight into recent developments. Note that all term premia fell in early 2012, with Chile and the US falling first, but the other three soon following. This persisted until mid-2013 when a 


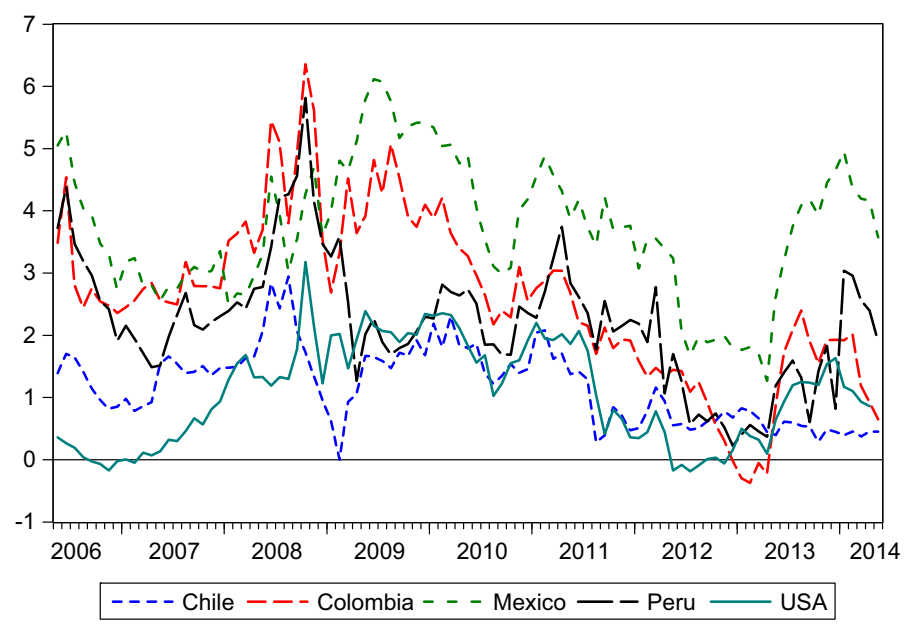

Fig. 9 Ten-year term premia estimates for Chile, Colombia, Mexico, Peru, and USA. Source Authors' calculations

sharp rise in term premia is detectable everywhere except for Chile. It seems likely that the fall is associated with turbulence in the Euro area, with considerable worries about the possibility of sovereign debt default there and the search for alternatives. The rise in 2013 coincides with the announcement of possible tapering by the US Federal Reserve.

In Table 2 we show the correlation of the two-year term premia estimates between our selected countries as well as with the US and Brazil over the maximum available sample periods. We include Brazil, a further Latin American inflation targeter. However, Brazil has a much higher inflation target (4.5\%) with wider tolerance bands and is perceived to have been less successful in achieving the target than the four main cases we consider (see De Pooter et al. 2014). ${ }^{7}$ At this horizon Mexican and particularly Colombian term premia are significantly positively correlated with US term premia. Brazilian term premia also turn out to be strongly positively correlated with the US. This complements the narrative in Guarn et al. (2014), who point to a negative correlation between Colombian and US yields; our numbers suggest the term premia remained positively correlated. The observed negative correlation in yields seems to be driven entirely by interest rate expectations.

This pattern is also evident at the 10-year horizon (Table 3). However, it is also apparent that both Chilean and Peruvian term premia are largely uncorrelated with the US at the ten-year horizon and even perhaps negatively correlated at the 2-year one. Unsurprisingly, a case can be made that neighboring countries seem more correlated at all horizons and there is a clear ranking in correlation with the US. ${ }^{8}$

\footnotetext{
7 We estimated a model for Brazil over essentially the same sample period as our other examples, but only report correlations here. Full results are available on request.

${ }^{8}$ If we calculate rolling correlations pairwise north-to-south, the correlations still fall, although a little less markedly.
} 
Table 3 Ten-year term premia cross correlations. Source Authors' calculations

Absolute $t$ statistics in parenthesis

\begin{tabular}{lllllll}
\hline & US & Brazil & Chile & Colombia & Mexico & Peru \\
\hline US & 1 & & & & & \\
& - & & & & & \\
Brazil & 0.58 & 1 & & & & \\
& $(6.86)$ & - & & & & \\
Chile & 0.15 & 0.42 & 1 & & & \\
& $(1.45)$ & $(3.26)$ & - & & & \\
Colombia & 0.69 & 0.59 & 0.45 & 1 & & \\
& $(9.23)$ & $(7.05)$ & $(4.87)$ & - & & \\
Mexico & 0.71 & 0.38 & 0.19 & 0.84 & 1 & \\
& $(9.73)$ & $(3.93)$ & $(1.91)$ & $(14.77)$ & - & \\
Peru & 0.17 & 0.64 & 0.53 & 0.57 & 0.36 & 1 \\
& $(1.64)$ & $(8.10)$ & $(6.08)$ & $(6.74)$ & $(3.71)$ & - \\
\hline
\end{tabular}

Chile in particular seems different; term premia there have not recovered since 2011 which explains the decreasing correlation with the US.

It is also the case that over particular periods of stress there turns out to be stronger correlation with the US. This is evident from Fig. 10 where we plot 2-year rolling correlations of the 10-year term premia with the US. From 2010 onward Colombia was temporarily much more correlated with the US but has recently returned to previous values. Chile has been much less correlated with the US as term premia have not responded to US monetary conditions.

Taken together the results seem to indicate that there was relatively little impact on longer term expectations from the financial crisis for the Latin American economies that we study. There was considerable variation in the term premia over this period, but except for Mexico, term premia seem a great deal lower post-crisis. If there has been an effect on long-term bond yields from globally adopted

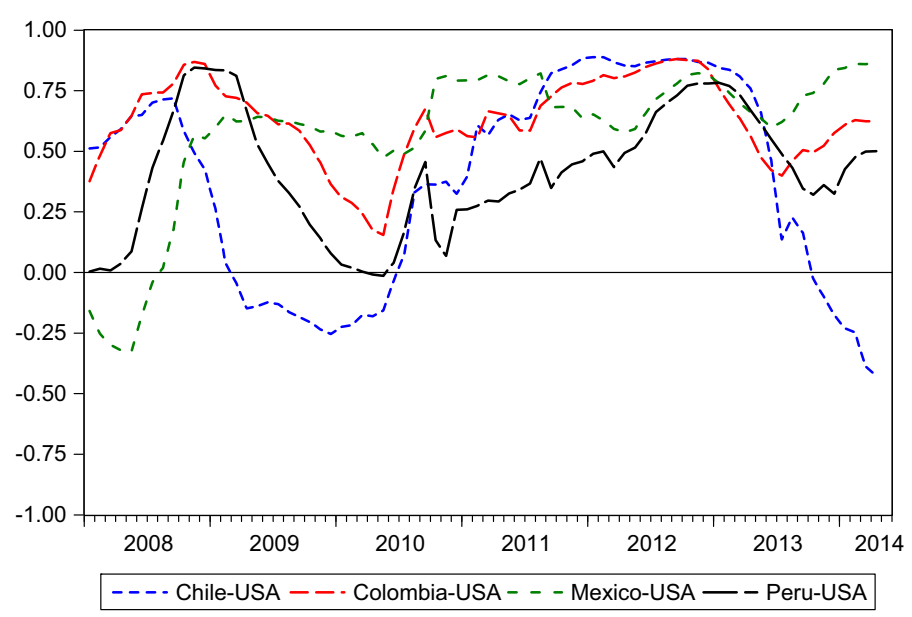

Fig. 10 Two-year rolling correlations of the ten-year term premia. Source Authors' calculations 
unconventional monetary policy measures, as suggested by Guarn et al. (2014), the ACM model attributes them entirely to reduced term premia. Increased term premia in the US since the onset of anticipated tapering seem to have raised term premia everywhere except Chile. But in none of the countries we study have there been apparent fluctuations in long-term inflation expectations and hence equilibrium nominal interest rates. Why have Chilean term premia failed to respond to the recent upturn? Ceballos et al. (2014) estimate term premia using the method suggested by Joslin et al. (2014) which are very similar to ours. They present some VAR evidence that Chilean premia are sensitive to US ones. However, they too document the lack of recent correlation. The apparent success of Chile in decoupling from US term premia suggest an avenue for future study.

\section{Conclusions}

We use the empirical approach due to ACM to estimate dynamic term structure models for four Latin American countries (Chile, Colombia, Mexico and Peru). To our knowledge, this is the first time this methodology has been applied to a cross section of Latin American countries. Using estimated coefficients from the widely used Nelson-Siegel term structure model, we generate synthetic bond-price contracts and use them to calculate a set of principal components. From these, we can calculate the implied affine yield curves and decompose them into implied term premia and interest rate expectations. Our results point towards stable long-run interest rate expectations, with movements in term premia accounting for most of the observed variation in yields. Term premia in all four countries have declined since 2006, despite the onset of the global financial crisis in 2008. We find evidence of a comovement of term premia across the four countries for the longer dated securities. While there is some comovement of term premia with the US, the dominant effect seems to be domestic monetary policy, which may well be due to the inflation targeting framework employed by the central banks in all four countries.

Acknowledgments We would like to thank Tom Belsham and Keith Corpe for help with the data, Andrew Meldrum for useful discussions on the empirical methodology and seminar participants at the 2014 LACEA-LAMES meeting for comments. Two referees, an associate editor and the editor made excellent suggestions to improve the paper.

Open Access This article is distributed under the terms of the Creative Commons Attribution License which permits any use, distribution, and reproduction in any medium, provided the original author(s) and the source are credited.

\section{References}

Adrian T, Crump RK, Mills B, Moench E (2014) Treasury term premia: 1961-present. Liberty Street Economics

Adrian T, Crump RK, Moench E (2013) Pricing the term structure with linear regressions. J Financ Econ 110(1):110-138 
Ang A, Piazzesi M (2003) A no-arbitrage vector autoregression of term structure dynamics with macroeconomic and latent variables. J Monet Econ 50(4):745-787

Ceballos L, Naudon A, Romero D (2014) Nominal term structure and term premia: evidence from Chile. In: Working Paper 60911. MPRA

De Pooter M, Robitaille P, Walker I, Zdinak M (2014) Are long-term inflation expectations well anchored in Brazil, Chile and Mexico? Int J Central Bank 10(2):337-400

Diebold FX, Rudebusch GD (2013) Yield curve modeling and forecasting: the dynamic Nelson-Siegel approach. Princeton University Press, Princeton

Ellingsen T, Söderström U (2001) Monetary policy and market interest rates. Am Econ Rev 91(5):1594-1607

Guarn, A, Moreno JF, Vargas H (2014) An empirical analysis of the relationship between US and Colombian long-term sovereign bond yields. In: Working Paper 822. Central Bank of Colombia

Gürkaynak R (2014) Discussion of "Are long-term inflation expectations well anchored in Brazil, Chile and Mexico?". Int J Central Bank 10(2):401-403

Gürkaynak RS, Sack B, Wright JH (2007) The US treasury yield curve 1961 to the present. J Monet Econ 54(8):2291-2304

Hammond G (2012) State of the art of inflation targeting, 4th edn. Handbook No 29, Centre for Central Banking Studies, Bank of England

Joslin S, Priebsch M, Singleton K (2014) Risk premiums in dynamic term structure models with unspanned macro risks. J Financ 69(3):1197-1233

Joyce MA, Lildholdt P, Sorensen S (2010) Extracting inflation expectations and inflation risk premia from the term structure: a joint model of the UK nominal and real yield curves. $J$ Bank Financ 34(2):281-294

Nelson CR, Siegel AF (1987) Parsimonious modeling of yield curves. J Bus 60(4):473-489

Svensson LEO (1995) Estimating forward interest rates with the extended Nelson-Siegel method. Sver Riksbank q Rev 3:13-26

Wickens M (2008) Macroeconomic theory: a dynamic general equilibrium approach. Princeton University Press, Princeton 